Proceedings of the Operational Research Society Simulation Workshop 2021 (SW21)

M. Fakhimi, D. Robertson, and T. Boness, eds.

DOI: https://doi.org/10.36819/SW21.043

\title{
DEVELOPING A HYBRID SIMULATION MODEL USING BOTH PARSIMONIOUS AND HIGHLY DESCRIPTIVE APPROACHES: REFLECTIONS FROM THE TRANSPORT INDUSTRY
}

\author{
William Jones \\ Kathy Kotiadis \\ Jesse O'Hanley \\ Kent Business School \\ University of Kent \\ Canterbury, Kent, CT2 7FS, UK
}

\begin{abstract}
We put forward some initial thoughts about using both parsimonious and highly descriptive approaches to engage stakeholders during the development of a hybrid simulation study in the transport industry. The hybridisation we discuss involved combining discrete-event and agent-based simulation. We discuss how both parsimonious and highly descriptive modelling approaches, which are seemingly incompatible, were used in the development of a hybrid model to help facilitate stakeholder engagement. In our experience stakeholders with limited understanding of the system being modelled engaged with more ease when presented with highly descriptive approaches. When working with stakeholders with a better understanding, parsimonious approaches can be beneficial. We also discuss potential techniques for managing the complexity of large simulation projects by adapting ideas from software development to help modellers work with stakeholders.
\end{abstract}

\section{INTRODUCTION}

Developing a model of a complex system requires a significant investment of time, expertise and expense (Robinson 2004). For an organisation undertaking such an investment, often new expertise will need to be introduced into the organisation to develop the desired model. When introduced, the modeller(s) will inevitably need to engage with stakeholders across the organisation to define the system to be modelled, identify its boundaries, decompose the system into various sub-systems, processes and activities, and map their interconnections (Tako and Kotiadis 2015). In a complex organisation, these steps will inevitably involve participation of many stakeholders. This is not especially problematic when developing discreteevent simulation (DES) models given the emergence of facilitation literature such as PartiSim (Tako and Kotiadis 2015) or system dynamics (SD) given the extensive research in group model building (GMB) (Rouwette and Vennix 2011) but more ambiguous when it comes to hybrid simulation modelling given the limited literature on it.

In this study, we discuss using both parsimonious (Vandekerckhove et al. 2015) and highly descriptive (Edmonds and Moss 2005) approaches to engage stakeholders during the development of a hybrid DES and agent-based simulation (ABS) model based on our experience in the transport industry. Our primary contribution is to add our experience to the very limited pool of papers discussing the development of hybrid simulation models with stakeholders.

This study reflects on work conducted with Eurostar International Limited (EIL). EIL is the only high-speed railway company operating international train services between London and continental Europe via the Channel Tunnel. Its core destinations including Paris, Brussels, Lille and Amsterdam. Further, it operates services to Disneyland Paris and runs seasonal trains to the south of France and the French Alps. 
We write the main body of this paper reflectively with a deliberately abstract style such that the reader can imagine how the ideas being discussed could apply to applications they have interest in, rather than being distracted by the specific case we reflect on. We include some footnotes to provide detail about the specific case where the extra context might be helpful.

The paper proceeds as follows. First, we provide some background and a review of the relevant academic literature (Section 2). Next, we summarise our experience of working with a large number of stakeholders and facilitating their involvement in the modelling lifecycle and put forward some techniques we used to aid the development of the hybrid model (Section 3). We go on to provide a discussion on how both parsimonious modelling (Vandekerckhove et al. 2015) and highly descriptive modelling approaches (Edmonds and Moss 2005) can be used within the same hybrid simulation model to increase engagement with and confidence in the modelling process (Section 4). Finally, we give some concluding remarks (Section 5).

\section{BACKGROUND}

The more complex a model becomes the more difficult it is usually to control and, in turn, gain insights about the fundamental workings of the system being modelled. A parsimonious modelling approach attempts to overcome this difficulty by designing the simplest possible model to achieve the required level of explanatory or predictive power (Vandekerckhove et al. 2015). If a parsimoniously designed model cannot produce outputs reflective of reality, it should first be asked whether the model itself is reflective of reality and or whether the modellers understanding of the system is correct before adding more complexity to the model (Edmonds 2000). This approach is often summarised by the adage "Keep It Simple Stupid" or KISS. Broadly the KISS approach recommends that a modeller should develop the simplest model possible and progressively add more complexity only when the simple model is shown to be inadequate

In contrast to KISS, Edmonds and Moss (2005), propose the "Keep it Descriptive Stupid" (KIDS) paradigm. Using a KIDS approach, a modeller should start by developing a model that is highly detailed and the most accurate reflection of the real system as possible, only simplifying this description when there is evidence and sufficient understanding to do so. When modelling a complex system, this inevitably means the initial model must be large and intricate. They argue that if simplifying from the start, some feature that is left may later turn out to be important.

Regardless of which modelling approach is adopted, the benefits of involving stakeholders in the simulation development lifecycle, in particular DES models, are well documented (Eldabi, Paul, and Young 2007; Fone et al. 2003; Jun, Jacobson, and Swisher 1999; Gunal and Pidd 2005; Lowery et al. 1994; Wilson 1981; Kotiadis et al. 2014; Robinson et al. 2014) and failing to do so can often result in findings not being accepted or acted upon (Brailsford and Vissers 2011; Fone et al. 2003; Young et al. 2009). Tako and Kotiadis (2015) present guidance for involving stakeholders throughout the lifecycle of developing a DES model. Their approach advocates engaging stakeholder through structured workshops to inform model design.

Surprisingly, there is little, if any, literature formally exploring the benefits of involving stakeholders in the lifecycle of ABM studies. However, it has been noted that ABM allows and facilitates a more direct correspondence between what can be observed by the stakeholders and what is modelled (Edmonds and Moss 2005). When applied to ABM, the descriptive nature of the KIDS approach aligns naturally with a participative, stakeholder-driven approach to model construction and validation (Barreteau, Bousquet, and Attonaty 2011). Highly descriptive ABMs have the advantage that their straight-forward correspondence with the real system provides a form of face validation (Edmonds and Moss 2005).

To harness the various benefits of different modelling approaches, hybrid simulation models have gained in popularity in recent years (Mustafee et al. 2017, Brailsford 2015, Brailsford et al. 2018). These are conceptual models, implemented in specialised software, that combine more than one simulation paradigm. Siebers et al. (2010) notes that ABM is well suited "when the goal is modelling the behaviours of individuals in a diverse population". DES, on the other hand, is known to be able to accurately represent a system 
involving stochastic events and processes governed by known input parameters. Consequently, models combining ABM with DES are particularly useful for representing complex organisations, often in service industry settings (Brailsford 2014), where several, seemingly autonomous entities operate according to their own set of events and processes and where their interactions cause complex system behaviours to emerge.

Summarising the causal factors of low stakeholder engagement, Jahangirian et al. (2015) identify "difficulty with understanding and working with simulation tools, techniques and models" as a key issue. When building a hybrid simulation model of a large organisation or other complex systems, inevitably not all stakeholders can be involved during all stages of the development lifecycle. It is likely that at each stage, the modeller will need to engage different stakeholders or re-engage stakeholders who have been out of touch for a period of time. As such, there is a need to design models and present model design choice to stakeholders in a way that easily enables them to engage and can help bridge the "communication gap" (Jahangirian et al. 2015) between modeller and stakeholders.

With this in mind, there is a clear need to understand how best to present complicated ideas and models to stakeholders in order to encourage involvement and gain trust. In the following section, we reflect on our experience of developing a hybrid simulation model for a large public transport organisation. We consider the stakeholders' views on the different modelling methodologies that were employed and discuss techniques used to aid working with stakeholders.

\section{MANAGING THE COMPLEXITY OF ENGAGING STAKEHOLDER IN COMPLEX MODEL'S}

We present here the experience of a modeller engaging with stakeholders in the development of a hybrid simulation model. We recount the level of stakeholders' engagement with each modelling approach and the stakeholders' beliefs about what could be achieved from modelling. Domain-driven design, encapsulation and test driven development are all techniques used by software developers when collaborating on complex software projects. We take these methods and discuss how they can be re-purposed as tools for managing the implementation of hybrid simulation modelling project that require engagement with many stakeholders and stakeholder buy-in.

The hybrid model we reflect on used an ABM and DES approach to represent the organisation's operations. The ABM structure represents the many sub-systems of the organisation as autonomous agents ${ }^{1}$. Within most of these sub-system agents, a DES model is defined that captures the processes and events of that sub-system ${ }^{2}$. Other agents provide data or make policy decisions regarding the operation of the system (see Fig. 1). In parallel to the simulation, other analytic techniques common to operations research were also introduced to the organisation. The organisation had no prior experience of these types of simulation or operations research techniques.

\subsection{Stakeholder Perspectives}

During the development of the hybrid simulation model the modeller was required to engage, broadly speaking, with two distinct groups of stakeholders. The first group of stakeholders were experts in specific areas (i.e., one sub-system of the organisation). The modeller needed to engage with them to develop simulations that represented the sub-system of interest to a level of detail acceptable to the stakeholders. This had to be repeated, in turn, for each sub-system. Further, when dealing with these stakeholders, the modeller needed to satisfy them that the system-level model containing their sub-system of interest was also accurately represented. These stakeholders did not necessarily have an expert understanding of the internal working of other components of the system. Additionally, the modeller was required to liaise with

\footnotetext{
${ }^{1}$ EIL is made up of many geographically separate sub-systems such as stations, depots, trains, the control room, etc which operate autonomously. All of these must operate together seamlessly in order for the service to be successfully delivered. Each one of these individual sub-systems is captured as an individual agent within the model.

${ }^{2}$ For example, when a train arrives in a station in the model this triggers the start of a DES model capturing the activities involved in the turn around of a train as can be observed in EIL's stations, e.g., unloading of passengers, followed by cleaning and restocking, followed by security sweep, followed by loading of new passengers.
} 


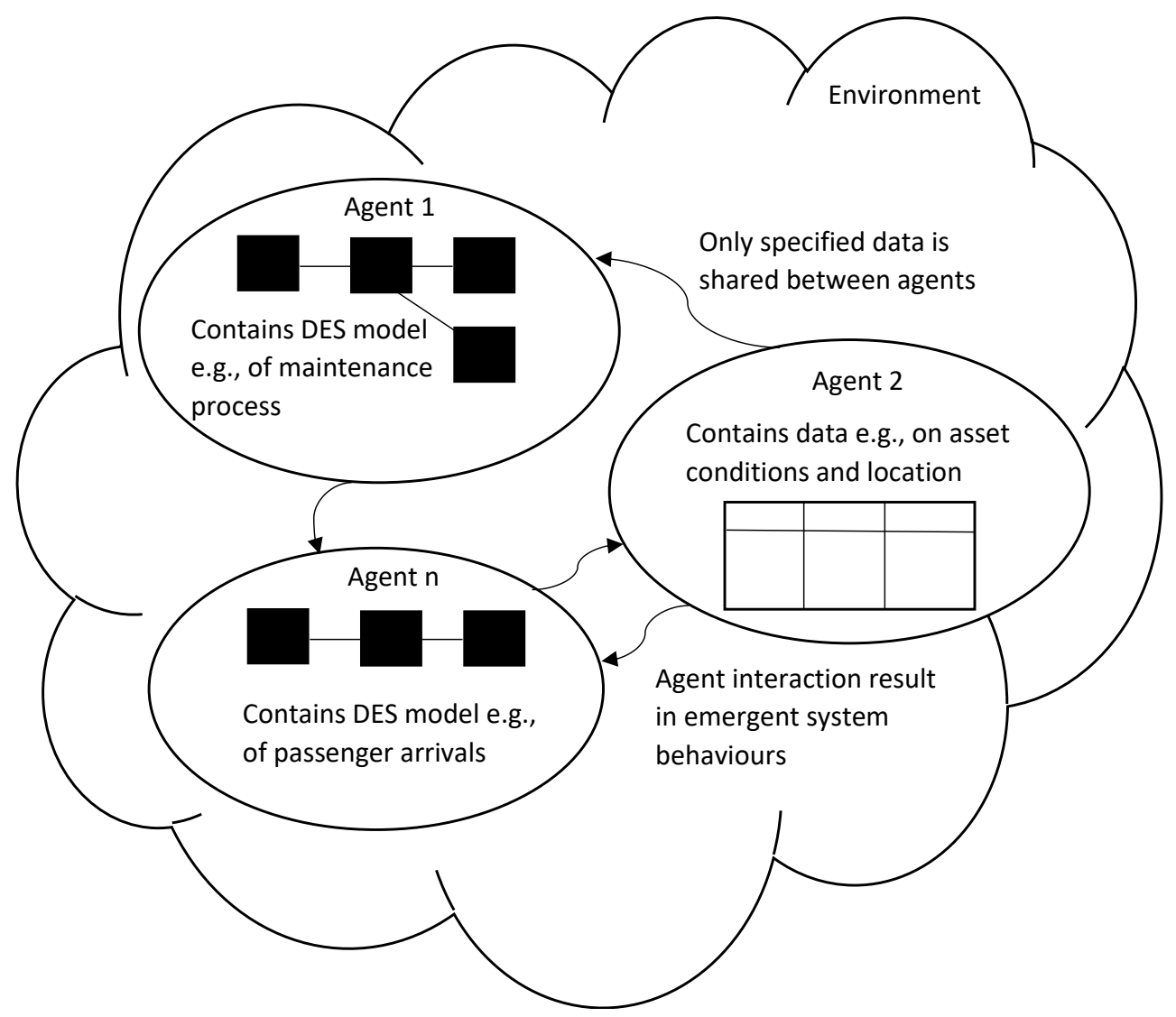

Figure 1: A highly simplified illustration of the developed hybrid simulation model structure.

a second group of stakeholders. Their interest differed from the first group. They were interested in the combined operation and behaviours of all the interacting sub-systems, more than any specific sub-system. This situation is likely common in that these two groups of stakeholders will be encountered in many types of organisations. The first group of stakeholders are usually those working in or managing a specific area or process, while the second group mostly include the organisation's senior management. These groups of stakeholders have different involvement with the system and, hence, different perspectives on its operation. However, based on personal experience, both share a similar understanding of how modelling is capable of capturing the main elements of a system and how it can benefit their own set of interests. A more detailed comparison of stakeholder's views on the modelling methods that were used is shown in Tab. 1. We acknowledge that the modeller's views and explanation may have influenced those of the stakeholders ${ }^{3}$.

One key insight gleaned during initial scoping work was that stakeholders' ability to engage with a particular level of the model (system versus sub-system level) was dependant on their expertise in the system level being modelled. Of the two modelling approaches, a highly descriptive approach was found to be easier for stakeholders to engage with when they are non-experts due to the clear correspondence between the observable system and the model (Edmonds and Moss 2005). When stakeholders had expertise in a certain sub-system, however, they were much more comfortable to see the sub-system modelled using

\footnotetext{
${ }^{3}$ EIL is a geographically distributed organisation. Each sub-system e.g., the Paris terminal or London maintenance depot, will be managed and operate by a group of stakeholders who, due to their vast experience operating and running that sub-system day to day, have an expert knowledge of how it works. Those particular stakeholders, however, do not necessarily have an expert knowledge of how other sub-systems operate or the various sub-systems interact. Other groups of stakeholders (i.e., senior leadership) within EIL to try to look at the organisation holistically and ensure all sub-systems operate together seamlessly such that the service can run smoothly.
} 
Table 1: Comparison of stakeholders views of modelling methods.

\begin{tabular}{|c|c|c|c|}
\hline Comparison Measure & Analytical Modelling & $\begin{array}{l}\text { Discrete Event Mod- } \\
\text { elling }\end{array}$ & Agent Based Modelling \\
\hline $\begin{array}{l}\text { Ontology: To do with } \\
\text { the stakeholders as- } \\
\text { sumptions about how } \\
\text { the system being mod- } \\
\text { elled is made up and } \\
\text { what the stakeholders } \\
\text { assumes can exist. (i.e., } \\
\text { how a valid representa- } \\
\text { tion of the system can } \\
\text { be achieve). }\end{array}$ & $\begin{array}{l}\text { A mathematical func- } \\
\text { tion describing the rela- } \\
\text { tionship between an in- } \\
\text { put and an output. }\end{array}$ & $\begin{array}{l}\text { The system can be de- } \\
\text { fined by a series of } \\
\text { events / process that oc- } \\
\text { cur in a know / definable } \\
\text { order. An abstraction } \\
\text { of the systems events } \\
\text { / processes bounded by } \\
\text { known parameters. }\end{array}$ & $\begin{array}{l}\text { The system consists } \\
\text { of several independent } \\
\text { components or sub sys- } \\
\text { tems, however, their op- } \\
\text { erations may impact on } \\
\text { each other. A de- } \\
\text { scriptive representative } \\
\text { of each component of } \\
\text { the real system. }\end{array}$ \\
\hline $\begin{array}{l}\text { Epistemology: To do } \\
\text { with the stakeholders } \\
\text { beliefs about how the } \\
\text { model could be used to } \\
\text { their benefit. Is the } \\
\text { method concerned with } \\
\text { finding out about ob- } \\
\text { jective facts and data } \\
\text { or ideas and phenom- } \\
\text { ena that have no external } \\
\text { reality; i.e., phenomena } \\
\text { that can be interpreted. }\end{array}$ & $\begin{array}{l}\text { For a given set of system } \\
\text { inputs the expected sys- } \\
\text { tem outputs can be gen- } \\
\text { erated, however, they } \\
\text { may be limited in their } \\
\text { utility, and accuracy as } \\
\text { the results are likely } \\
\text { to provide theoretical } \\
\text { bounds, that may be sig- } \\
\text { nificantly different from } \\
\text { what is achievable in re- } \\
\text { ality. }\end{array}$ & $\begin{array}{l}\text { Experimentation can } \\
\text { recreate the events and } \\
\text { processes of the real } \\
\text { system and generate } \\
\text { insight into how to } \\
\text { improve them. The } \\
\text { method tests a clearly } \\
\text { defined set of param- } \\
\text { eters and the data } \\
\text { generated is accepted } \\
\text { as accurate. }\end{array}$ & $\begin{array}{l}\text { Experimentation can } \\
\text { recreate phenomena } \\
\text { seen to occur in the } \\
\text { real system, providing a } \\
\text { method of investigating } \\
\text { these and generating } \\
\text { understanding, hence, } \\
\text { improving decision } \\
\text { making. Emergent } \\
\text { system characteristics } \\
\text { depend on the agents } \\
\text { behaviours, hence, if } \\
\text { each agent is mod- } \\
\text { elled appropriately the } \\
\text { system characteris- } \\
\text { tics should accurately } \\
\text { reflect the real world. }\end{array}$ \\
\hline $\begin{array}{l}\text { Axiology: What is } \\
\text { the stakeholders under- } \\
\text { standing of the purpose } \\
\text { or use of the models? Is } \\
\text { the intention to explain } \\
\text { or predict the real sys- } \\
\text { tem, or to understand it? }\end{array}$ & $\begin{array}{l}\text { Can be used to pro- } \\
\text { duce statistical infor- } \\
\text { mation concerned with } \\
\text { overall system perfor- } \\
\text { mance. The data gen- } \\
\text { erated provides insight } \\
\text { from which further the- } \\
\text { ories can be extracted. }\end{array}$ & $\begin{array}{l}\text { The data generated } \\
\text { should be comparable } \\
\text { to data generated by a } \\
\text { physical implementa- } \\
\text { tion. Parameters in the } \\
\text { model can be modified, } \\
\text { as they could be in } \\
\text { the real system and, } \\
\text { hence, the impact can } \\
\text { be observed. }\end{array}$ & $\begin{array}{l}\text { A model that accurately } \\
\text { describes the system can } \\
\text { produce accurate infor- } \\
\text { mation. The results gen- } \\
\text { erated aim to identify } \\
\text { phenomena and provide } \\
\text { understanding of their } \\
\text { origins. A validated } \\
\text { model could predict the } \\
\text { impact of changing sys- } \\
\text { tem inputs. }\end{array}$ \\
\hline
\end{tabular}


a more abstract or parsimonious modelling approach when these were developed in a stakeholder-driven manner.

Based on this, it was ultimately decided to build a hybrid ABM and DES simulation model. The advantage of the hybrid model was that it combined within the same model both a highly descriptive modelling approach (Edmonds and Moss 2005), mainly through ABM, and a parsimonious modelling approach (Vandekerckhove et al. 2015), mainly through DES. Agents within the ABM were defined for each sub-systems of the organisation. Various DES models were then built into the agents by working closely with key stakeholders who had expertise in a given sub-system. In many cases, this was done through a series of structured workshops as recommended by Tako and Kotiadis (2015). Typically, DES sub-models were developed parsimoniously by focusing on the key events and processes of the sub-system as defined by the stakeholders. These stakeholders had expert knowledge of these systems and understood how events and processes could be abstracted to relatively simple models ${ }^{4}$. Conversely, the ABM structure containing these agents was highly descriptive of the organisational structure. Note that due to the size of the organisation, it was simply not possible to involve all stakeholders in all phases of model development. However, due to the highly descriptive ABM structure, regardless of one's specific area of expertise, all stakeholders could see correspondence between the model and the organisation and so were satisfied that it was a reflective and valid model ${ }^{5}$. On several occasions, stakeholders enquired about a sub-system outside their specific expertise. The modeller was happy to show this to them and explain that that part of the model had been developed with experts in that sub-system. Stakeholders were mostly happy to accept this. If they did make any comments, these were raised with the sub-system experts and, if necessary, appropriate changes made.

\subsection{Techniques for Managing Complexity}

Throughout the model development process we used techniques from software development, adapting them slightly, to help manage the complexity of the model building process. Three key techniques used were domain-driven design, encapsulation and test driven development. We discuss each of these and reflect on their benefits to the model development process as follows.

Domain-driven design (Evans 2004) is common practice in software engineering and aims to design software in such a way that it is clear what its purpose is and help manage complexity for developers. This is achieved by focusing software development projects on the core domain (defined sphere of knowledge) and domain logic and by basing software designs on a conceptual model of the true domain that has been devised by technical and domain experts working in collaboration address specific domain problems. Here, software engineers are collaborating with stakeholders to develop the best product (e.g., collaborating with accountants to develop accountancy software). This is similar to modellers collaborating with stakeholders to develop a simulation, however, the significant difference with a simulation study is the need for validation by stakeholders and their acknowledgement that the underpinning conceptual model and subsequent simulation model implementation provide an accurate reflection of reality to ensure they are willing to accept and act on experimentation findings. This need for stakeholder validation of simulations underpinning a conceptual model does not exist in other forms of software engineering.

\footnotetext{
${ }^{4}$ For example, due to the expertise in the events and processes involved, the team running EIL's London maintenance depot could understand how the depots operation could be abstracted to a simple DES model. In the model a train would arrive with maintenance requirements and leave when they were fixed. The time it spent in the depot would depend on the type of maintenance required, the available resources in the depot (i.e., engineers) and other maintenance demands at that time (i.e., other trains in the depot). The depot had a maximum capacity for the number of trains that could be accommodated, if that was reached no more trains could enter. They would have to either go to another depot, or if that was not possible, queue until capacity became available.

${ }^{5}$ Due to the highly descriptive nature all EIL stakeholders could see how the model directly mapped to parts of the organisation. They could see that each sub-system was contained within the model.
} 
Closely related is the idea of encapsulation (Horstmann and Cornell 2002). Encapsulation, a fundamental concept in object-oriented programming, proposes combining data and methods that impact / use that data within a single distinct unit (e.g., a Java class). This concept separates the internal workings of a defined object from the rest of the programme. Only defined inputs or outputs are visible outside of the unit.

A number of ideas can be borrowed from domain-driven design and encapsulation concepts in the field of software engineering to help simulation modellers better engage with stakeholders. The structure of the hybrid simulation approach used in this study was designed to be easily understandable by stakeholders. The domain-driven design approach to developing software that makes clear what its purpose is fits well with the KIDS approach proposed by Edmonds and Moss (2005). As Edmonds and Moss (2005) note, this highly descriptive modelling approach enables a "direct correspondence between what is observed and what is modelled", which helps with face validation of the model. The ABM structure of the hybrid simulation model developed represents, as accurately as possible, the internal structure of the transport industry organisation. Further, stakeholders could relate to the different components of the system being encapsulated in the hybrid model that was developed, agents often performed complex operations (e.g., by running DES sub-models), but only certain, explicitly defined information was shared between agents. This reflected the accepted reality of the organisation. Sub-systems operate largely autonomously but share relevant information (e.g., information is shared with other parts of the organisation regarding when maintenance work on a particular asset is due to be completed, but specific details of all the maintenance process are not shared, as they were not relevant to other parts of the business). In several instances, the model could have been simplified by breaking from the domain-driven design and encapsulation principles. However, consistently following these principles to maintain a descriptive similarity between the model structure and the real system and encapsulating data in a manner reflective of the organisation's operation facilitated stakeholders' understanding and aided their engagement in the modelling process.

Domain-driven design and encapsulation have a further advantage, which links to a third concept from software engineering, test-driven development. Model development is a highly iterative process (Willemain 1995, Balci 1994, Robinson 2013). When developing a complex model of a large organisation, inevitably several versions of the model will be required and it is highly likely that the underpinning conceptual model will evolve as the modeller continually engages with more, newly introduced stakeholders. Test-driven development (Astels 2003, Beck 2003) is a process for developing software by proposing very specific test cases then adapting the software so that it can 'pass' these tests (i.e., fulfil specified criteria). This is typically done in relatively short cycles and does not allow any additions to the software that are not proven to meet requirements. This process is used by software developers, who both pose and complete the tests, to ensure changes to the software work as intended. Simulation development of a large organisation can similarly develop in a test-driven way. When working with stakeholders or introducing new stakeholders during the development of a model, inevitably new requirements for the model or scenarios to simulate will emerge. During the development of the hybrid simulation model we developed, when this situation occurred, collaboratively the modeller and the stakeholders posed a 'test', (i.e., a scenario observed in the organisation's operation to be replicated in simulation). The model was then adapted to replicate this. This test-driven development is likely easier to do if the model has been developed considering domain-driven design and encapsulation. With these concepts appropriately implemented, changes can be made within a specific part of the model to satisfy new requirements of stakeholders without having to make a fundamental change to the conceptual model. This approach acknowledges that initial engagement with stakeholders by the modeller will fail to capture all the relevant information, something that is inevitable in a large organisation. Designing the model code in this manner enables iterative development as the conceptual model evolves.

\section{DISCUSSION}

Edmonds and Moss (2005), propose the KIDS approach to model development as a counter to the widely used KISS approach. It is generally believed that these represent incompatible perspectives on how models 
should be developed. On the contrary, we incorporated both of these approaches during the development of a single, hybrid simulation model, switching between the two to encourage engagement in the modelling process and ensure stakeholders are happy to accept the final model as valid.

In our case study, due to the size of the organisation and scope of the project, it was impossible to engage all relevant stakeholders throughout the development lifecycle of the hybrid simulation model. Further, it was inevitable that the final model was going to be complicated and difficult for non-experts to engage with. With this in mind, our model was structured to maximise stakeholder engagement. The model design considered stakeholders ontological, epistemological, and axiological perspectives (see Tab. 1). Stakeholders could clearly identify the mostly autonomous sub-systems of the large organisation. However, few stakeholders within the organisation had a clear understanding of how the multitude of interactions of the many component sub-systems or why these exist within the organisation's overall operation. This reflects the ontological perspective of agent-based modelling (Macal and North 2008) that was explained to and accepted by the stakeholders (see Tab. 1) and, hence, why a highly descriptive agent-based model structure was used. Operations of the various sub-systems were contained within the agents of the model structure and captured using a DES approach. Here, DES models were developed collaboratively with stakeholder through structured workshops following the approach of Tako and Kotiadis (2015). The DES approach captured these sub-systems as a series of time-dynamical events and processes. Stakeholders involved in the development of these DES models were experts in the individual sub-systems. They were happy to accept this abstract ontological view of the system due to their expert knowledge of the processes and events involved.

Of course, here we are reflecting on just one example of a hybrid simulation study. The hybrid highly descriptive and parsimonious approach used supported by the techniques from software development discussed (domain-driven design, encapsulation, test-driven development), help successfully deliver a modelling study the organisation was satisfied with and able to realise significant benefits from. Different groups of stakeholders from other industries will have unique problems, different worldviews and other preconceptions. The approach we have discussed may not be suitable for their problems. If that is the case, we hope at least this paper will provide other simulation practitioners with ideas they can adapt.

Crooks, Castle, and Batty (2008) note that models should be based on theory and that the traditional role of a model is to represent theory into a form whereby it can be tested and refined. In effect, a computer simulation model provides a laboratory for virtual experimentation. This is typically encapsulated in a parsimonious KISS modelling (Vandekerckhove et al. 2015) approach. However, this traditional scientific method is not always followed, particularly with agent-based models which are often used to develop theory. This is in line with the KIDS approach Edmonds and Moss (2005) propose. It should be acknowledged that any model attempting to be highly descriptive is inevitably forced to make simplifications, many of which will inevitably be hidden within model design assumptions and the software implementation (Crooks, Castle, and Batty 2008).

\section{CONCLUSION}

When developing complex simulation models of large organisations there is a need to design and present the models to stakeholders in a way that encourages their engagement. We present here an example of successfully developing a hybrid simulation model for a large transport industry organisation that helped to facilitate stakeholder engagement. We found that stakeholders were able to engage with models developed parsimoniously when they were experts in the sub-system being modelled. When stakeholders had less expertise in the system, a highly descriptive modelling approach was easier for them to engage with and found to promote validity of the model. In the hybrid simulation developed, both the parsimonious and highly descriptive approaches where used to better reflect the variability of stakeholders' expertise. We also explain how methods from software engineering (domain driven design, encapsulation, and test-driven development) were used to support working with stakeholders and aid the development of a highly complex hybrid simulation model. 
Jones, Kotiadis, and O'Hanley

\section{REFERENCES}

Astels, D. 2003. Test driven development: A practical guide. Prentice Hall Professional Technical Reference. Balci, O. 1994. "Validation, verification, and testing techniques throughout the life cycle of a simulation study". Annals of Operations Research 53 (1): 121-173.

Barreteau, O., F. Bousquet, and J.-M. Attonaty. 2011. "Role-Playing Games for Opening the Black Box of Multi-Agent Systems : Method and Lessons of Its Application to Senegal ...". Journal of Artificial Societies and Social Simulation 4 (2).

Beck, K. 2003. Test-driven development: by example. Addison-Wesley Professional.

Brailsford, S. 2014. "Modeling Human Behaviour - An (ID)entity Crisis?". In Proceedings of the Winter Simulation Conference, edited by A. Tolk, S. Y. Diallo, I. O. Ryzhov, L. Yilmaz, S. Buckley, and J. A. Miller, 1539-1548. Piscataway, New Jersey: IEEE.

Brailsford, S. 2015. "Hybrid simulation in healthcare: New concepts and new tools". In Proceedings of the Winter Simulation Conference, edited by L. Yilmaz, W K V. Chan, I Moon, T. M K. Roeder, C. Macal, and $M$ D. Rossetti, 1645-1653. Piscataway, New Jersey: IEEE.

Brailsford, S., and J. Vissers. 2011. "OR in healthcare: A European perspective". European Journal of Operational Research 212 (2): 223-234.

Brailsford, S. C., T. Eldabi, M. Kunc, N. Mustafee, and A. F. Osorio. 2018. "Hybrid simulation modelling in operational research: A state-of-the-art review". European Journal of Operational Research 278 (3): 721-737.

Crooks, A., C. Castle, and M. Batty. 2008, nov. "Key challenges in agent-based modelling for geo-spatial simulation". Computers, Environment and Urban Systems 32 (6): 417-430.

Edmonds, B. 2000. "Complexity and scientific modelling". Foundations of Science 5 (3): 379-390.

Edmonds, B., and S. Moss. 2005. Multi-Agent and Multi-Agent-Based Simulation, Volume 3415 of Lecture Notes in Computer Science. Berlin, Heidelberg: Springer Berlin Heidelberg.

Eldabi, T., R. J. Paul, and T. Young. 2007. "Simulation modelling in healthcare: reviewing legacies and investigating futures". Journal of the Operational Research Society 58 (2): 262-270.

Evans, E. 2004. Domain-driven design: tackling complexity in the heart of software. Addison-Wesley Professional.

Fone, D., S. Hollinghurst, M. Temple, A. Round, N. Lester, A. Weightman, K. Roberts, E. Coyle, G. Bevan, and S. Palmer. 2003. "Systematic review of the use and value of computer simulation modelling in population health and health care delivery". Journal of Public Health 25 (4): 325-335.

Gunal, M., and M. Pidd. 2005. "Simulation Modelling for Performance Measurement in Healthcare". In Proceedings of the Winter Simulation Conference, edited by M.E. Kuhl, N.M. Steiger, F.B. Armstrong, and J.A. Joines, 2663-2668. Piscataway, New Jersey: IEEE.

Horstmann, C. S., and G. Cornell. 2002. Core Java 2: Volume I, Fundamentals. Pearson Education.

Jahangirian, M., S. Borsci, S. G. S. Shah, and S. J. E. Taylor. 2015. "Causal factors of low stakeholder engagement: a survey of expert opinions in the context of healthcare simulation projects". SIMULATION 91 (6): 511-526.

Jun, J. B., S. H. Jacobson, and J. R. Swisher. 1999. "Application of discrete-event simulation in health care clinics: A survey". Journal of the Operational Research Society 50 (2): 109-123.

Kotiadis, K., A. A. Tako, and C. Vasilakis. 2014. "A participative and facilitative conceptual modelling framework for discrete event simulation studies in healthcare". Journal of the Operational Research Society 65 (2): 197-213.

Lowery, J., B. Hakes, W. Lilegdon, L. Keller, K. Mabrouk, and F. McGuire. 1994. "Barriers to implementing simulation in health care". In Proceedings of the Winter Simulation Conference, edited by J.D. Tew, S. Manivannan, D.A. Sadowski, and A.F. Seila, 868-875. Piscataway, New Jersey: IEEE.

Macal, C. M., and M. J. North. 2008, dec. "Agent-based modeling and simulation: ABMS examples". In 2008 Winter Simulation Conference, 101-112: IEEE. 
Mustafee, N., S. Brailsford, A. Djanatliev, T. Eldabi, M. Kunc, and A. Tolk. 2017. "Purpose and Benefits of Hybrid Simulation: Contributing to the Convergence of Its Definition". In Proceedings of Winter Simulation Conference, edited by W.K.V. Chan, A. D’Ambrogio, G. Zacharewicz, N. Mustafee, G. Wainer, and E. Page, 1-15. Piscataway, New Jersey: IEEE.

Robinson, S. 2004. Simulation: The practice of model development and use. Chichester: John Wiley \& Sons.

Robinson, S. 2013. "Conceptual modeling for simulation". In Proceedings of the Winter Simulation Conference, edited by R. Pasupathy, S.-H. Kim, A. Tolk, R. Hill, and M. E. Kuhl, 377-388. Piscataway, New Jersey: IEEE.

Robinson, S., C. Worthington, N. Burgess, and Z. J. Radnor. 2014. "Facilitated modelling with discrete-event simulation: Reality or myth?". European Journal of Operational Research 234 (1): 231-240.

Rouwette, E. A. J. A., and J. A. M. Vennix. 2011. Group Model Building, 484-496. New York, NY: Springer New York.

Siebers, P. O., C. M. Macal, J. Garnett, D. Buxton, and M. Pidd. 2010. "Discrete-event simulation is dead, long live agent-based simulation!". Journal of Simulation 4 (3): 204-210.

Tako, A. A., and K. Kotiadis. 2015. "PartiSim: A multi-methodology framework to support facilitated simulation modelling in healthcare". European Journal of Operational Research 244 (2): 555-564.

Vandekerckhove, J., D. Matzke, and E.-J. Wagenmakers. 2015, dec. Model Comparison and the Principle of Parsimony, Volume 1. Oxford University Press.

Willemain, T. R. 1995. "Model Formulation: What Experts Think About and When". Operations Research 43 (6): 916-932.

Wilson, J. C. T. 1981. "Implementation of Computer Simulation Projects in Health Care". Journal of the Operational Research Society 32 (9): 825-832.

Young, T., J. Eatock, M. Jahangirian, A. Naseer, and R. Lilford. 2009. "Three Critical Challenges for Modeling and Simulation in Healthcare". In Proceedings of the Winter Simulation Conference, edited by M. D. Rossetti, R. R. Hill, B. Johansson, A. Dunkin and R. G. Ingalls, 1823-1830. Piscataway, New Jersey: IEEE.

\section{AUTHOR BIOGRAPHIES}

WILLIAM JONES was a Knowledge Transfer Partnership (KTP) Associate at Kent Business School, University of Kent in partnership with Eurostar International Limited. He received a B.Sc. Eng. in Mechanical Engineering from Cardiff University, in 2013 and an EngD. from the University of Bristol, in 2019. He is now a postdoc at the University of Sydney. His research interests include modelling and simulation, the process of model development and automation. His email address is william.jones@ sydney.edu.au.

KATHY KOTIADIS is a Reader (Associate Professor) in Management Science / Operational Research at Kent Business School, University of Kent. She has a B.Sc. (Hons) in Management Science and a $\mathrm{PhD}$. in Operational Research both from the University of Kent. Her main research interests include discrete event simulation modelling applied to health care and simulation model development using problem structuring methods. In 2009, she was awarded the KD Tocher Medal by the UK OR society for the best simulation paper published in the Journal of Simulation in 2007-08. Her email address is k.kotiadis@kent.ac.uk.

JESSE O'HANLEY is a Professor of Environmental Systems Management at Kent Business School. His research focuses on the development and application of optimisation and simulation techniques for environmental management, facility location, transportation and logistics. He has authored dozens of articles and other publications covering a wide range of theoretical and applied topics. He is the 2015 winner of the prestigious EURO Excellence in Practice Award in recognition for the development of a state-of-the-art decision support for river connectivity restoration. His email address is j.ohanley @ kent.ac.uk. 